\title{
Huijun ZOU, Qinghua LIANG \\ Establishing distinctive theories and methods of design science rooted in Chinese traditional culture
}

\author{
(C) The Author(s) 2020. This article is published with open access at link.springer.com and journal.hep.com.cn
}

\begin{abstract}
The human social development saw the formation of five unique civilizations, with the latter forming their own distinctive cultures. China's traditional culture is its most fundamental ideological weapon for solving problems. The Chinese are good at comprehensive thinking, dialectical thinking, and systematic analysis. These ideological weapons can solve the problems of formal science and technology and create scientific and technological achievements on par with global advanced scale. Ancient China is filled with original scientific and technological achievements, which strongly prove ancient China's possession of its own science and technology different from that of Western Renaissance. Therefore, a comprehensive understanding of science, technology, experience, and intuition is necessary. The long-held superstition regarding the West, the lack of confidence, self-denial, blind imitation of ideas, and shackles must be thrown away. Only then can we take the road toward an authentic Chinese creative design as we learn from others.
\end{abstract}

Keywords traditional Chinese culture, comprehensive thinking, systematic analysis, Needham's Grand Question, ancient Chinese scientific and technological achievements, design driving innovation, design theoretical thinking, design dialectical methods

\section{Introduction}

The five ancient civilized nations in the world, namely, China, ancient Greece, ancient Egypt, ancient India, and Mesopotamia, formed during the development of human society. Traditional Chinese culture is pregnant with Chinese civilization. Chinese culture has distinct char-

Received July 15, 2019; accepted December 3, 2019

Huijun ZOU ( ( ), Qinghua LIANG

School of Mechanical Engineering, Shanghai Jiao Tong University, Shanghai 200240, China

E-mail: hjzou@sjtu.edu.cn acteristics, which emphasize integral consciousness and systematic analysis. Guided by these unique ways of thinking, Chinese classical works, such as the I Ching or $Y i$ Jing (Book of Changes), the Huangdi Neijing (Yellow Emperor's Inner Canon), the Tao Te Ching, and Confucianism, came into the world 2000 years ago. These philosophical masterpieces containing Chinese characteristics are filled with Chinese philosophy and wisdom and are extensive and profound. Chinese wisdom also contributed to The Art of War-Thirty-Six Stratagems, an ancient book of design science with design philosophy features. Numerous examples of innovative design abound in Chinese classical fictions; the Romance of the Three Kingdoms contains many vivid design cases. Many landmark creative design paradigms emerged in ancient China, such as the Dujiangyan irrigation system and the water-driven astronomical clock tower.

From the 3 rd century to the 1600 s, China has made profound scientific and technological achievements, reaching advanced levels that matched the rest of the world. Joseph Needham, a former member of the Royal Academy of Sciences, wrote a seven-volume book titled Chinese History of Science and Technology, highly praising the scientific and technological achievements of ancient China.

The Qing Dynasty of China slowly declined 150 years ago. To strike down Western powers and to revitalize China, people with lofty ideals advocated overthrowing the Qing Dynasty and making China a republic by achieving political democracy, scientific progress, and wholesale westernization, fully denying traditional Chinese culture. The total denial of traditional Chinese culture led to selfdiffidence, low self-esteem, and blind faith in the West. On the road toward scientific development, the Chinese lack national confidence and consequently imitated others, largely suppressing the inheritance of Chinese traditional culture and the development of Chinese creative and innovative thinking. Our education reforms have long followed others, swinging chaotically between the Soviet Union and European and American countries without our 
own features. We have also followed foreign countries in the selection of subjects for scientific research for a long time, filling the vacancies left by others with few research projects genuinely reflecting Chinese identity. Forthrightly, we should rise above foreign countries and achieve authentic Chinese scientific and technological achievements. An aptitude for design innovation is crucial if a nation were to stand on its own two feet. Only advanced design ideas and methods can help China rid itself of regression and surpass developed countries. Indeed, overtaking at corners risks collision, and overtaking by switching lines is better. Nonetheless, only by searching for a suitable approach of surpassing others is a country's fundamental option.

Culture is the root of a country. Different cultures produce different social ideologies. Culture determines a country's basic philosophical thinking and methodology of knowing and changing the world and governing the society and the country. Thousands of years of Chinese culture have cultivated a unique wisdom, allowing the effective understanding, discrimination, judgment, processing, and invention of objective things. Chinese culture is also our valuable spiritual wealth. Chinese wisdom is the spiritual pillar and mental strength of our nation. For instance, the dialectical thinking and system cognition methodology of the I Ching or Yi Jing lay emphasis on holism, intuition, abstraction, and generalization, which are beneficial for the exploration of an ever-changing world. The Confucian doctrine of the mean is a universally acknowledged, moderate, and workable principle, a very important concept of being a man and of doing things. The Huangdi Neijing discusses the interrelationships among the universe, the Earth, and human beings from a macroscopic perspective; sets out the yin and yang and five elements, etiology, and health preservation; and tells us how to apply a holistic, systematic, and intuitional thinking ability to solve complicated problems found in human life activities. The Tao Te Ching is a philosophical work expounding the universe, life, and politics. It puts forward a viewpoint that "man follows the Earth, the Earth follows the Universe, the Universe follows the Tao, and the Tao follows only itself." Finally, it presents the unity of the universe, the Earth, and human beings, and indicates the laws of development and change of all things and the thoughts espoused in dialectical materialism.

In short, traditional Chinese culture is our root and the source of Chinese wisdom. We must strengthen cultural confidence, master the essence of traditional Chinese culture, overcome difficulties, use Chinese wisdom to overcome difficulties in the creative and innovative design of various things, and achieve remarkable innovation results to pioneer a genuine Chinese creative design.

Ieoh Ming Pei, a world-renowned Chinese-American architect, is a master of design amalgamating Eastern and Western cultures. His works have been deeply influenced by traditional Chinese culture. He wrote in the preface to the I. M. Pei: Complete Works: "I've been away from China for more than 80 years, and most of my architectural career for more than 70 years has been in the United States and Europe. That's it, I'm a Western architect profoundly influenced by Chinese culture. I deeply love beautiful Chinese poetry, paintings and gardens, which have inspired me a lot. I've been honored to take part in several design projects in China, ranging from the early Fragrant Hill Hotel to the recent Suzhou Museum, and during that period, I'd been committed to exploring a way to modernize Chinese architecture. Chinese architecture has always been rooted in the Chinese tradition, growing new sprouts. It's the hope of Chinese architecture." The above words have fully proven the effects of a splendid traditional culture on one's life. From another viewpoint, traditional culture and Chinese wisdom can foster theories and methods of a design science.

\section{Deepening the understanding of science and technology: An in-depth analysis of the Needham's Grand Question}

Joseph Needham, a former member of the Royal Academy of Sciences, had worked on the history of science and technology in China for a long time. He wrote a sevenvolume book titled Chinese History of Science and Technology, which clearly expounded that China's scientific and technological achievements had been in the forefront of the world before the 16th century. His findings are highly remarkable and with profound contribution. He vigorously promoted the contribution of China's scientific and technological achievements to the world, which is conducive to enhancing the Chinese confidence and selfesteem.

However, Needham also had his doubts and raised the "Needham's Grand Question" (also known as "Needham's Puzzle"). He asked, "Why did modern science develop only in European civilization instead of Chinese or Indian civilization?" Needham explained that scientific breakthroughs only took place in Europe during the Renaissance period, which is connected with the particular social, ideological, and economic situations of Europe. Therefore, the riddle can never be interpreted as flaws of the Chinese people's thoughts or philosophical tradition.

Based on "Needham's Puzzle," one can say that "China has no science," or China can never give birth to modern science. The analysis of Needham's Puzzle can be illustrated from the following three aspects: What is science? What is the relationship between science and technology? What is the methodology of scientific research?

From the 1st century B.C. to the 15th century A.D., Chinese civilization has more advanced science and 
technology than that in Western civilization. Chinese science had emerged by then. Without Chinese science, where did the scientific and technological achievements of ancient China come from? Regarding the relationship between technology and science, modern people think that technology and science are inseparably connected, and technology is based on science. Technology comes from science, and technology itself is science. From the methodology of scientific research, the starting point of Western modern scientific research emphasized the importance of analysis and demonstration and focuses on local or individual in-depth research, which is an effective method for scientific research. From the very beginning, Chinese scientific research highlighted holistic system, dialectical thinking, and complex reasoning, as well as the whole and overall situation. Such a methodology originated from China, as described in many classics of science and philosophy, inclusive of the I Ching or Yi Jing, the Tao Te Ching, Confucianism, and the Huangdi Neijing. Indeed, it is a substantial contribution to the treasure of human wisdom.

The consensus of modern humanity is that the Western and Chinese sciences each has its own merits and that the scientific methods of whole-part, synthesis-analysis, and demonstration-reasoning are indispensable for scientific research. Traditional Chinese culture is good at dialectical thinking, holistic thinking, and systematic research, opening a new path toward innovating design.

\section{Numerous original scientific and technological achievements in ancient China}

After analyzing the "Needham's Puzzle", we will look into the original scientific and technological achievements of ancient China. These achievements fully demonstrate that Chinese science has a long history. The Chinese have constantly, albeit, quietly developed science and have promoted social progress in this long period of nearly 2000 years.

In October 2010, two scientists, one Chinese and one American, came to Institute for History of Natural Sciences, Chinese Academy of Sciences. They hoped to supplement the scientific milestones published by the American Association for the Advancement of Science, because no Chinese invention was included in the scientific milestones. Therefore, the institute established a research group for important scientific inventions and creations in ancient China with the following inclusion criteria: 1) With originality highlighted; 2) reflecting the advanced level of ancient science and technology development; and 3) having an important influence on the world civilization.

A total of 88 important scientific and technological inventions in ancient China were identified by 300 experts and scholars and officially announced to the media on July
14, 2016. In addition, a book titled Important Scientific Inventions and Creations in Ancient China, was published. These inventions are divided into three major categories:

1) Twenty-nine scientific discoveries and creations, such as the rod calculus (the Spring and Autumn Period), pinhole imaging (in the 4th century B.C.), Gougurongyuan (no later than the early Eastern Han Dynasty), and Qin Jiushao's method (1247 A.D.);

2) Forty-three technological inventions, such as pig ironbased steel smelting (the early Spring and Autumn period), paper making (the early Western Han Dynasty), seismograph (132 A.D.), rocket-propelled fire arrow (no later than the Southern Song Dynasty); and

3) Thirteen engineering achievements, such as the Chimes of Marquis Yi of Zeng State (the early Warring States period), the Dujiangyan irrigation system (256 B.C. -251 B.C.), the Great Wall (with the construction period starting from the late Warring States period until the Qin Dynasty), and the Grand Canal (of which the section of the Sui and Tang Dynasties was opened in the early 7th century, while the Beijing-Hangzhou section was opened in 1293).

Notably, our ancestors also cultivated tea, rice, soybean, and orange. The cultivation techniques of these crops spread worldwide, and their contributions to the survival and development of human beings are not inferior to the four great inventions of ancient China.

Given these 88 major scientific and technological achievements, how then could we conclude that ancient China has no science? Ancient China's development level of science and technology in ancient China has been on the leading level worldwide for a long time. The development of science in turn promoted the considerable development of productive forces, and China's Gross Domestic Product (GDP) accounted for one third of the world's GDP at that time.

\section{Basic characteristics of scientific and technological innovation methodologies in ancient China}

The I Ching or Yi Jing, one of the world's earliest philosophical works, is recognized as an important book full of dialectical thinking and system cognition methodology. This book focuses on holism, intuition, abstraction, and generality and uses a symbol-character system to express a complex world. This book is useful when studying the changing universe. According to a German philosopher named Karl Theodor Jaspers, many great spiritual leaders and mentors, such as Sakyamuni in India, Jewish prophets in Israel, Pythagoras, Socrates, Plato, and Aristotle in ancient Greece, and Confucius and $\mathrm{Lao} \mathrm{Zi}$ in China, appeared in several important civilized nations of the world from 800 B.C. to 200 B.C. The thoughts of these 
great sages have influenced human life to this day. In fact, the I Ching or Yi Jing was approximately five or six hundred years earlier than the other philosophical works. The most important significance of the I Ching or Yi Jing lies in its provision of a worldview and methodology. Many thoughts of our nation can be traced back to the $I$ Ching or Yi Jing, such as the following famous quotation "The movement of heaven is full of power. Thus the superior man makes himself strong and untiring. The earth's condition is receptive devotion. Thus the superior man who has breadth of character carries the outer world." It compares the nature's vigorous movements with selfdiscipline and social commitment of human behaviors and activities.

Huangdi Neijing was written during the Spring and Autumn Period. This book summarizes the previous medical expertise before the Qin and Han Dynasties; combines the achievements of ancient philosophy and natural science; explains the relations among the universe, the Earth, and human beings from an objective perspective; and comes up with theories of yin and yang and the five elements, pulse manifestations, meridians and collaterals, and health preservation. This book also reflects simple ancient dialectical materialism thoughts and intuitive thinking ability with strong integral consciousness.

The Tao Te Ching, written by Lao Zi in the late Spring and Autumn period, is a philosophical book which expounds the universe, life, and politics and puts forward the law of the universe, the Earth, and human beings. "Man follows the Earth, the Earth follows the universe, the universe follows the Tao, and the Tao follows only itself." This book expresses the unity of the universe, the Earth, and human beings; it also subscribes to the ideals of dialectical materialism that all things follow their own rules of development, and change is a highly helpful reference for our design innovation research.

Confucianism is the dominant Chinese ideology and background of Chinese culture for more than 2000 years. Confucianism is extensive and profound, containing abundant wisdom of the universe, society, and life. Confucianism has a profound influence on traditional Chinese culture. For design innovation researchers, understanding the doctrine of the mean is important ("ZhongYong") and helpful in understanding the essence of Confucianism, acquiring dialectical thinking, solving problems, and mastering the profound wisdom of research problems. "Zhong" means "it is just right to the point, without over-reaching or under-reaching;" while "Yong" means a common principle that is easy and feasible, without requiring any change or any agile mastery. The doctrine of the mean requires that concrete problems require specific analysis without violating the principle, and an appropriate scale requires mastery. This doctrine is a kind of wisdom.

In accordance with this in-depth analysis, the funda- mental spirit of traditional Chinese culture is philosophical and full of dialectical thinking. It has the spirit of innovation, which is the wisdom of traditional Chinese culture. We should carry forward traditional Chinese culture because it provides our scientific and technological innovations with highly important guidance.

The basic characteristics of the philosophy and methodology of scientific and technological innovations in ancient China lie in the following:

1) Thinking of materialist dialectics: The principle "the Tao follows only itself" is a highly generalized thought of dialectical materialism, indicating that the occurrence and development of anything would be impossible without the objective world.

2) Integral consciousness and systematic thinking: To understand the changing laws of objective things, we should first consider the overall situation and system, which is called the big picture. When the entire situation is grasped clearly, detailed problems can be perfectly solved.

3) Highly generalizing and fully understanding the essence of things: These works are concise and simple, reflecting the wisdom of the ancients.

4) Paying attention to experience and intuition: Experience and intuition still play crucial roles in innovation and creation as long as we lift experience to a high level and rigorously judge the development and change of things.

5) Grasping fundamental rules and establishing systems: These works fully embody this method of scientific research and deserve our emulation.

Ancient Chinese ways of thinking emphasize integral consciousness, dialectical thinking, and systematic thinking. The ancient Chinese are good at mastering rules through improvements in experience and setting up of a new system through vast generalizations and intuition. Ancient Chinese collective consciousness is generally good at comprehensively dealing with problems, laying a solid foundation for Chinese science.

\section{The differences between Chinese and Western cultures:}

Chinese thinking is abstract and characterized by comprehensive research and strong integral consciousness. Westerners are adept at concrete analysis and demonstration, giving priority to partial research. Thus, Chinese science belongs to the comprehensive category, whereas Western sciences belong to the analytical and empirical categories. Commonly stated, one attaches importance to holism, whereas the other appreciates localism. In fact, Chinese and Western scientific thoughts each has its own merits. Chinese scientific thoughts emphasize the humanoriented dialectical thinking and systematic analysis. The latter prioritizes integral consciousness, which is beneficial to the establishment of the system of design theories and methods for a long-run holistic system, lifting design science to a new level, and allowing all design objects to 
reach optimum coordination and comprehensive optimization of the holistic system. Western scientific thoughts focus on analysis and demonstration as well as in-depth local or individual research, which is conducive to the deep understanding of the internal laws of each part and that of the wholeness from partialness. Therefore, Western scientific thoughts are also worth learning. Focusing merely on local or individual research will inevitably lead to a blind situation, and reaching the realm of the greatest and simplest truths will be difficult.

Traditional Chinese culture has earlier experienced the impact of Western culture for over 150 years. Total westernization forced China to take a detour. Now, we are slowly eliminating cultural inferiority, and we believe that the spring of cultural revival will usher in a new era.

\section{Importance and universality of design}

The development of human civilization has promoted the progress of human society, thereby improving human life. Human civilization is generally divided into material and spiritual civilizations. Material civilization refers to the level of human material life manifested as the improvements in the material production method and economic life. This civilization can also be interpreted as the sum of the material achievements of human beings in remaking nature, and its contents cover the development of social productive forces, the improvements in production tools and technologies, the expansion of production scale, and the accumulation of social wealth. Spiritual civilization refers to the sum of all spiritual achievements made by human beings in remolding the objective and the subjective worlds. The latter symbolizes the progress of human intelligence and morality. The achievements of spiritual civilization include cultural and ideological achievements. Cultural achievements include a series of developmental achievements, covering social and cultural knowledge, science, education, literature, art, and health and physical education; ideological achievements include ideological and political status, moral aspect, and social custom. Material and spiritual civilizations are derived from the ideas that people put forward to innovate and create according to requirements and conditions of developments. Specifically, design stimulates the development of human civilization.

Material civilization is largely objective and real; it is all sensible "things." Therefore, the design objects of material civilization are concrete "things," whereas those of spiritual civilization are abstract "affairs," taking the forms of cultural thoughts. Overall, design objects are of "things" and "affairs." Design should include the design for material and spiritual production. The creation of new things cannot happen without design, and the quality of design often largely determines the quality of new things.
Design provides an impetus to the progress of human civilization and to changing the world. Without a good design, the world would have not become so colorful and brilliant.

The universality of design means that design is everywhere. First, design is always present. The human race has continued to this day since the beginning of human civilization but cannot live without design. All kinds of simple tools in the ancient times, such as stone tools during the Paleolithic Age and plowing tools and woodware during the Neolithic Age, were devised to improve labor conditions. Ancient design focused on plow cutters, scoop waterwheels, water-propelled mills, ox and horses for handling and transportation, as well as paddlewheels and different winches. Modern design is reflected in power machinery, such as steamers, internal combustion engines, steam, and water turbines. Prominent examples of modern design include computers and spacecrafts. Different periods have different design contents. Second, design is everywhere. All human activities in production, scientific research, politics, culture, and daily life require design. Design satisfies human needs and promotes the development and progress of human society. Design is everywhere in the space for human activities. People have improved their home life with the excellent design of living utensils, have made cities beautiful with distinctive architectural design, have benefited mankind with all sorts of design of artificial intelligent technologies, and have explored the vast universe and deep space with fantastic spacecraft design. With time, the space for human design activities will expand further.

The concept that design is everywhere implies that design covers industrial, engineering, product, and architectural design, which are visible and tangible. Such qualities categorize this conceptual form as hardware design. Intangible concepts, such as politics, culture, and art are also covered by design, under the category of soft design.

\section{Complexity and system of design}

The universality and importance of design also determine the complexity of design.

Design seems complicated although it can be used to solve all kinds of problems relating to "affairs" and "things," while meeting the needs to promote the development of material and spiritual civilization of human society. People generally believe that the soul of design is innovation. Design is regarded as a complex process of innovation. Thus, we analyze the complexity of design from multiple perspectives. Then, we present an idea that requirements and goals of design are the starting and end points of design, which requires broad vision and profound ideas. 
Ieoh Ming Pei claimed spending nearly two years preparing for the design of the Suzhou Museum. The corresponding design innovation is carried out in each stage of the entire process. The complexity of design manifests the requirements in a wealth of scientific knowledge in specialized disciplines, multi-disciplinary humanistic knowledge, and even profound philosophical concepts and thoughts. Mastering various ways of innovative thinking and expertly using various innovation skills and methods are also required.

In conclusion, the ability to tap market demands and innovative thinking as well as a wealth of multidisciplinary knowledge and perseverance, are the cornerstones of a successful design. The key elements of success are extremely complex, and these requirements are changing and evolving dynamically. Thus, the complexity of design can be clearly seen.

Design objects are "affairs" and "things;" some are simple, whereas others are complicated. However, any design object is systematic, which is manifested in the system consisting of the operational environment for design objects and the population concerned and also in the system of design objects. All constituents of this system are interlinked and inter-played. The systematic quality of objects can make complicated and changeable design goals. Thus, design schemes are varied, and the design evaluation is comprehensive and complete.

The system of design objects requires the systematic dialectical thinking while designing. Design should focus on the overall functionality and consider the performance requirements of each individual constituent. Based on the basic requirements in wholeness, relevance, hierarchy, intentionality, and environmental adaptability of the system, a system solution is obtained. The design process of such objects is often of a multi-layer and multiconstituent design, inclusive of top-down and bottom-up iterative design.

The system of design objects is also reflected in the systematic evaluation of the implementation scheme. The design scheme of any system should not be an absolute optimization but a comprehensive optimization. Merely pursuing local optimization would not make global optimization, which is undesirable. The comprehensive optimization of the system achieves the best design goals using the comprehensive evaluation indicators and methodology. Meaning, the constituents of the system are mutually coordinated, adapted, and matched, thereby attaining the best design goals. Any best design is inseparable from the system of design.

\section{Innovation is the soul of design, and design is the means to achieve innovation}

Innovation and design depend on each other. Innovation is the soul of design, indicating the importance of innovation in the entire design process. Without innovation, design has no vitality; and without novelty, the design will not be competitive in the market. Design is an important means to achieve innovation, and the ideas and goals of innovations must be achieved through design.

Innovation is the soul of design, which is manifested in the following aspects:

1) Each stage of design has its own priorities and contents of innovation. The entire process of design is to advance the overall design in the form of innovation during the process of completing innovation tasks at different stages;

2) All kinds of innovative thinking are used to promote the design innovation at different stages; moreover, various innovative technologies are adopted for design innovation, thereby bringing the design to a high level;

3 ) The entire process of design is always pursuing unique and innovative comprehensive optimization results.

Design is an effective means of achieving innovation, which is embodied in the following aspects:

1) Achievement of conceptual innovation through the requirement and goal of design;

2) Achievement of conceptual design innovation through the conceptual design;

3) Achievement of detailed innovation through the design of each constituent;

4) Achievement of overall coordination innovation through the harmonious and coordinated design of thinghuman-environment;

5) Achievement of system evaluation and decision-making innovation through the evaluation system and methodology.

Design is taken as a means to implement innovation and the innovative idea to the utmost extent, thereby maximizing its value.

\section{Unity of the design process and methods}

Separation of the design of "affairs" from that of "things" is often impossible in human society. Therefore, a connected and unified thinking of the design of "affairs" and "things" is worth considering. Simply limiting design to the design of "things" is very one-sided and not good for attaining a rigorous understanding of the design nor for the accomplishment of a good design job.

In fact, the term "design" has long been used in the Records of the Three Kingdoms. Ancient Chinese interpreted design as "stratagems." Traditional Chinese culture has constantly attached great importance to comprehensive thinking. In addition, ancient Chinese were good at maneuvering stratagems, comprehensively considering the combination of the design of "affairs" and that of "things." For many complex design objects, separation of 
the design of "affairs" from that of "things" is actually difficult. Thus, design of "affairs" and that of "things" requires integration and unified consideration. The result is the unity of design, which requires a unified design framework model. The unified design framework model highly generalizes all kinds of design and is a profound understanding of design characteristics. Unity of design is necessary to explore and build design science.

From the research and analysis on many large and complex design projects, understanding the unity of design is worthy of attention. For the planning and construction of large- and medium-sized cities, attaching importance to the fusion of the design of "affairs" and that of "things" is conducive to the efficient, harmonious, balanced, and coordinated operation. Moreover, two large international airports, i.e., Kuala Lumpur International Airport (Malaysia) and Hong Kong International Airport (China), were thrown into chaos at the initial commissioning stage. From the viewpoint of design, these situations are worth pondering.

\section{Thoughts on building a theoretical system of innovative design with Chinese characteristics}

Building an authentic Chinese theoretical system of innovative design is our long-term goal, which requires that the soul and root of the theoretical system should originate from excellent traditional Chinese culture and from the Chinese philosophical concept of the unity of man and nature. The soul and root brand the theoretical system of innovative design with Chinese characteristics, which also happens with a newly sprouting bud.

China has vigorously introduced and popularized the advanced design theories and methods and design software products abroad since the reform and opening up, thereby boosting the development of Chinese design and methods. However, China continues to learn from and follow others. Even our research and development is on the basis of expanding and modifying the theories and methods of others, with very few unique and pioneering theories and methods of our own. In particular, few new design theories and methods containing Chinese features exist. Thus far, China has the world's second largest economy, and we must forge ahead in all aspects. Especially, the theoretical system of innovative design is unique. China's excellent traditional culture and unique philosophical thinking methods will lead us forward.

The Chinese are adept in design, thinking, and innovation. In Chinese paintings, freehand brushwork and blank space are intoxicating. Theories of traditional Chinese medicine, such as the "unity of man and nature" and "treatment based on different signs," have been regularly gaining popularity worldwide. In terms of design, ancient Chinese cultural essence and wisdom are also worth studying.

To build a theoretical system of innovative design that is authentically Chinese, we should think carefully on how to absorb Chinese wisdom and how to take excellent traditional Chinese culture as the root of our creative design and thus put forth new shoots. Taking the Chinese dialectical thinking and philosophical concept of the unity of man and nature as the soul stimulates the flourishing of our design. Thus, Chinese wisdom can be summarized into six points:

1) Seizing the fundamentals: We should develop good systematic thinking about all things through abstraction and generalization. How then do we unify design goals and objective requirements? Only when the fundamental is grasped will the design be perfected;

2) Taking a long-term perspective: The design must have a long-term vision rather than a pursuit of quick success. Paying attention to the unity of heaven, earth, and human is necessary as well as coordinating the harmony and balance between people and the environment. Moreover, the design of "affairs" and that of "things" should be integrated because these designs are often interconnected and inseparable.

3) Establishing concepts: A good design must be imaginative and highly general, with a pioneering concept and creative thinking. Progress means accepting change. A new idea will create a new working mechanism and perhaps a monument to the hearts of design aficionados.

4) Grasping the rules: This point is crucial to the success of design. We should rigorously understand and grasp the past, present, and future of design objects, as well as the inherent regularity of design objects, the relevance between design objects and the surrounding environment, and the harmony and compatibility between design object and human, as well as predict the future development of design objects. The design is likely at its best mastering all rules.

5) Design objects themselves are of a system, which constitutes a system with the surrounding environment and human beings. Therefore, the pursuit of balance and coordination among the constituents of such system is a design principle that we must follow. We must pursue harmony, perfection, and efficiency with unremitting efforts, as well as the formal and harmonious beauty, particularly harmonious inner and outer beauty. Seeking the balance and harmony in all things is the golden mean advocated by ancient Chinese. Everything must fit like a glove.

6) The authentic Chinese design theory system is pursued while building up the Chinese theoretical system of innovative design. Chinese characteristics must be fully reflected in the following aspects: Holism, dialectics, 


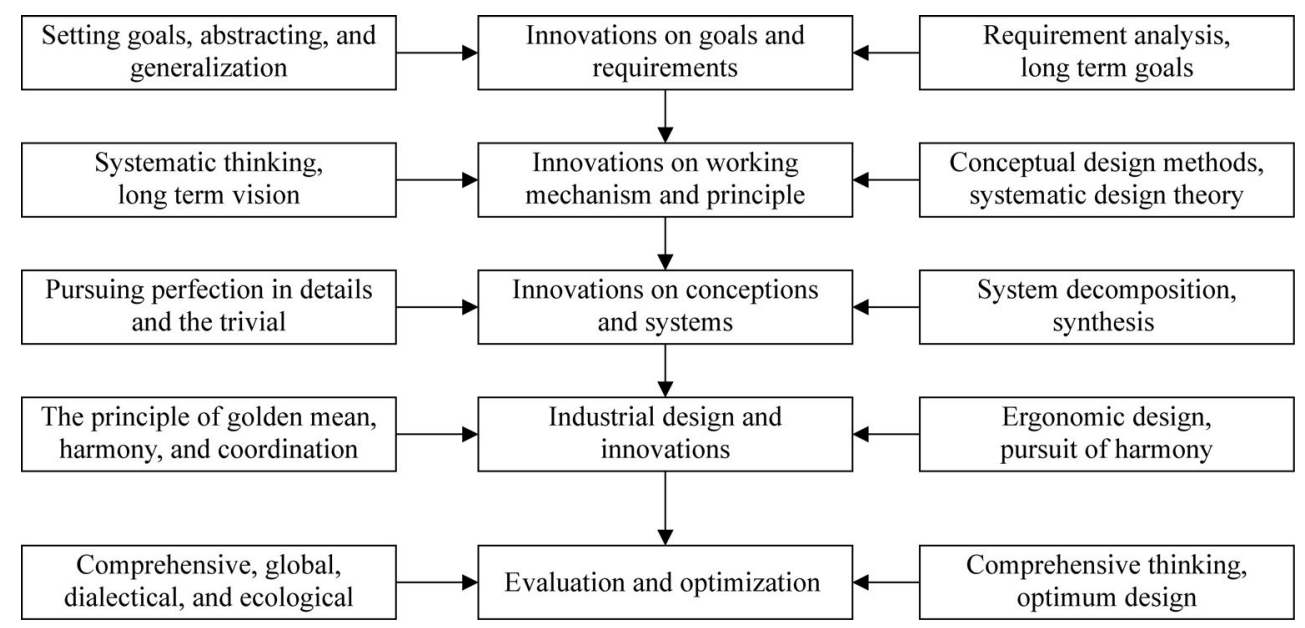

Fig. 1 Basic contents and process diagram of creative design.

man-nature unity, abstraction, and generalization. Figure 1 shows the basic contents and process diagram of creative design. Although little difference exists between Western and Chinese design in form, considerable difference exists in philosophical concepts, thinking modes, and solution methods of traditional culture. We should feel with our hearts and learn from others while fully utilizing our strengths, in the hope of building our own theoretical system.

\section{Conclusions}

The following preliminary results are obtained:

1) Design exists everywhere. Design contents are the products of the substantial integration and fusion of natural science and humanities. Designers should gain an extensive and rich knowledge base and comprehensive and creative intelligence.

2) Designers must be perfectly aware of the unity of the universe, the Earth, and human beings, humanism, globallocal consciousness, systematic or comprehensive thinking, and material dialectical thoughts. They must also possess an aptitude for philosophical, balanced, and coordinated thinking.

3) A design process model unifying the different categories of soft and hardware designs is established, which raises design theories to a certain scientific height and achieves a high level of technology by integrating the actual soft and hardware designs.

4) Innovation is suggested to be the soul of design, and design is a means of practical innovation. Innovation is the dialectics of design, and design is the methodology of innovation. Design and innovation are highly integrated. A pointless controversy on creative design and design innovation is unnecessary.

5) The role and value of design should be highly regarded, and design is the driving force and important means of the development of human material and spiritual civilization. Saying that design creates and pushes forward human civilization is not an exaggeration.

6) The greatest truths are the simplest. An important yardstick to delve into the theories and methods of design science is that making design theories and methods complicated and tedious often turns the corresponding research into its opposite. "Simplicity" and "One" actually constitute the essence of things and reflect human intelligence.

The preliminary conclusions demonstrate that the root and soul of Chinese culture can be fused into design theories and methods, thereby building an authentic Chinese design theoretical system and encouraging us to promote the development of China's scientific and technological undertakings with confidence.

Acknowledgements This article is licensed under a Creative Commons Attribution 4.0 International License, which permits use, sharing, adaptation, distribution and reproduction in any medium or format, as long as you give appropriate credit to the original author(s) and the source, provide a link to the Creative Commons licence, and indicate if changes were made.

The images or other third party material in this article are included in the article's Creative Commons licence, unless indicated otherwise in a credit line to the material. If material is not included in the article's Creative Commons licence and your intended use is not permitted by statutory regulation or exceeds the permitted use, you will need to obtain permission directly from the copyright holder.

To view a copy of this licence, visit http://creativecommons.org/licenses/ by/4.0/. 